Pesq. Vet. Bras. 28(3):174-182, março 2008

\title{
Surtos de Enteropatia Proliferativa Hemorrágica (Lawsonia intracelullaris) em suínos no Estado do Rio de Janeiro'
}

\author{
Ticiana N. França ${ }^{2,3}$, Carlos T. Ribeiro ${ }^{4}$, Pedro S. Bezerra Jr ${ }^{5}$, Jürgen \\ Döbereiner $^{6}$, Valíria D. Cerqueira ${ }^{7}$ e Paulo V. Peixoto ${ }^{4}$
}

\begin{abstract}
França T.N., Ribeiro C.T., Bezerra P.S., Döbereiner J., Cerqueira V.D. \& Peixoto P.V. 2008. [Outbreaks of Proliferative Haemorrhagic Enteropathy (Lawsonia intracelullaris) in swine in Rio de Janeiro state.] Surtos de Enteropatia Proliferativa Hemorrágica (Lawsonia intracelullaris) em suínos no Estado do Rio de Janeiro. Pesquisa Veterinária Brasileira 28(3):174-182. Centro de Ciências Biológicas e da Saúde, Faculdade de Medicina Veterinária, Universidade Estácio de Sá, Rio de Janeiro, RJ 22783-320, Brazil. E-mail: ticianafranca @ terra.com.br

Outbreaks of infection of swine with Lawsonia intracelullaris in the state of Rio de Janeiro are described. The symptomathology was characterized by bloody diarrhea with peracute course. Postmortem findings were pale organs and tissues, reticulate aspect of the ileum with its mucosa moderately thickened nad contained large amounts of partially coagulated blood. Histopathological examination revealed hyperplastic epithelial cell proliferation of the Lieberkühn crypts, sometimes associated with inflammatory and necrotic alterations. Immunohistochemistry demonstrated the presence of large amounts of bacteria in the cytoplasm of the cryptal epithelial cells. $L$. intracellularis was also seen by ultramicroscopic examination. These outbreaks occurred in 1987 and this is the first report of the disease in the state of Rio de Janeiro.
\end{abstract}

INDEX TERMS: Lawsonia intracellularis, Proliferative Haemorrhagic Enteropathy, swine, Rio de Janeiro.

RESUMO.- Descrevem-se surtos de Enteropatia Proliferativa Hemorrágica causados por Lawsonia intracellularis em suínos no Estado do Rio de Janeiro. A sintomatologia caracterizou-se por diarréia sanguinolenta com evolução superaguda. À necropsia verificaram-se íleo de aspecto

\footnotetext{
${ }^{1}$ Recebido em 13 de novembro de 2007.

Aceito para publicação em 10 de dezembro de 2007.

${ }^{2}$ Centro de Ciências Biológicas e da Saúde, Faculdade de Medicina Veterinária, Universidade Estácio de Sá, Rio de Janeiro, RJ 22783320, Brasil. *Autor para correspondência: ticianafranca@terra.com.br

${ }^{3}$ Universidade Federal do Rio de Janeiro, Faculdade de Medicina, Depto Cirurgia, Centro de Cirurgia Experimental, Bloco J, 2o andar, Ilha do Fundão, Rio de Janeiro, RJ 21944-970.

${ }^{4}$ Universidade Federal Rural do Rio de Janeiro (UFRRJ), Seropédica, RJ 23890-000, Brasil.

${ }^{5}$ Depto Medicina Veterinária, Universidade Federal de Lavras (UFLA), Campus Universitário, Cx. Postal 37, Lavras, MG 37200-000, Brasil.

${ }^{6}$ Convênio "Projeto Sanidade Animal Embrapa/UFRRJ", Seropédica, RJ 23890-000.

${ }^{7}$ Escola de Medicina Veterinária, Campus Castanhal, Universidade Federal do Pará (UFPA), Rua Maximino Porpino 1000, Castanhal, PA 68743-080, Brasil.
}

reticulado, com mucosa moderadamente espessada e grande quantidade de sangue parcialmente coagulado, além de marcada palidez de órgãos e carcaça. O exame histológico revelou proliferação hiperplásica das células epiteliais das criptas de Lieberkühn, por vezes, associada a alterações inflamatórias e necróticas. A imunohistoquímica demonstrou presença da bactéria, em grande quantidade, dentro do citoplasma das células epiteliais das criptas. $L$. intracellularis também foi visualizada pela ultramicroscopia. Os surtos ocorreram em 1987 e essa é a primeira descrição da enfermidade no Estado do Rio de Janeiro.

TERMOS DE INDEXAÇÃO: Lawsonia intracellularis, Enteropatia Proliferativa Hemorrágica, suínos, Rio de Janeiro.

\section{INTRODUÇÃO}

A Enteropatia Proliferativa Suína (EPS) é um termo utilizado, desde 1931, para identificar um complexo de doenças (Biester \& Schwarte 1931). Apesar deste longo período, apenas recentemente, devido, entre outros fatores, a 
dificuldades da manutenção do microorganismo in vitro (Gebhart et al. 1983, Dittmar et al. 2003), definiu-se Lawsonia intracellularis como seu agente etiológico (Lawson \& Rowland 1974, Love et al. 1977, Gebhart et al. 1983, McOrist et al. 1989, Mapother et al. 1987). Atu almente, EPS é considerada a doença de maior importância econômica em diversas regiões suinocultoras na Europa (Jacobson et al. 2003), nos Estados Unidos, cujas perdas anuais eram estimadas entre 10 e 20 milhões de dólares (Mapother et al. 1987), no Japão (Koyama et al. 2006) e, ainda, no Brasil, onde foi detectada na Região Sul (Morés et al. 1985, Barcellos et al. 1992, Driemeier et al. 2002, Faccini et al. 2005).

São relativamente recentes os estudos epidemiológicos que descrevem $L$. intracellularis como causa de enfermidades em ampla variedade de hospedeiros como coelhos (Umemura et al. 1982, Duhamel et al. 1998, Schauer et al. 1998), cavalos (Cooper et al. 1997, Wuersch et al. 2006) e diversas espécies de aves e mamíferos silvestres (Cooper et al. 1997, Lemarchand et al. 1997).

Em suínos, o complexo EPS apresenta-se sob várias formas (Rowland \& Lawson 1992) e inclui alterações descritas como Adenomatose intestinal suína (Biester \& Schwarte 1931), Enteropatia proliferativa hemorrágica (Rowland \& Lawson 1975), Enterite necrótica (Rowland \& Lawson 1992) e lleíte regional (Alderton 1993). A lesão comum a todas as formas é intensa hiperplasia dos enterócitos das criptas do íleo (principalmente), jejuno, ceco ou cólon. A presença de bacilos curvos ou retos no citoplasma apical dos enterócitos das criptas proliferadas é característica (McOrist et al. 1996). De forma geral, a EPS é considerada uma enfermidade silenciosa, porém associada a perdas econômicas significativas. O sintoma descrito como característico de doença crônica é a perda de peso lenta e progressiva, resultante da diarréia (Guedes et al. 2002a) ou da diminuição do apetite (Love et al. 1977). $\mathrm{Em}$ alguns casos, principalmente aqueles cujas alterações se estendem além da adenomatose, a doença cursa com sintomas adicionais de forma variada, como febre, associada a abortos (Mauch \& Bilkei 2005) ou, simplesmente, morte súbita (Love et al. 1977). Essa variação pode ocorrer mesmo dentro de um rebanho (Jensen et al. 2000, McOrist 2005). O objetivo deste trabalho é descrever os aspectos clínico-patológicos de surtos de enteropatia proliferativa em suínos, ocorridos em 1987, no Estado do Rio de Janeiro.

\section{MATERIAL E MÉTODOS}

Os estudos anátomo-patológicos foram realizados no Setor de Anatomia Patológica (SAP) e as avaliações bacteriológicas no Laboratório de Bacteriologia, ambos do Convênio "Projeto Sanidade Animal (PSA) Empresa Brasileira de Pesquisa Agropecuária/Universidade Federal Rural do Rio de Janeiro" (Embrapa/UFRRJ), Km 47, Seropédica, RJ. Os exames imunohistoquímicos e ultraestruturais realizaram-se no Departamento de Patologia da Faculdade de Veterinária, Universidade Federal do Rio Grande do Sul, e no Setor de Microscopia

\section{Quadro 1. Suínos encaminhados ao SAP, PSA-Embrapa/ UFRRJ para diagnóstico anátomo-patológico}

\begin{tabular}{cccc}
\hline $\begin{array}{c}\text { Suíno } \\
\text { no. }\end{array}$ & $\begin{array}{c}\text { Referência } \\
\text { SAP }\end{array}$ & Data & Município \\
\hline 1 & 24187 & 19.3 .1987 & Petrópolis \\
2 & 24189 & 19.3 .1987 & Petrópolis \\
3 & 24202 & 11.4 .1987 & Petrópolis \\
4 & 24221 & 15.5 .1987 & Seropédica \\
5 & 24227 & 26.5 .1987 & Rio de Janeiro (Campo Grande) \\
6 & 24261 & 13.7 .1987 & Rio de Janeiro (Campo Grande) \\
7 & 24266 & 14.7 .1987 & Rio de Janeiro (Campo Grande)
\end{tabular}

Eletrônica do Departamento de Patologia da Universidade Federal de Santa Maria, respectivamente.

Sete suínos (Quadro 1), com idades entre 45 dias e 8 meses, de ambos os sexos, provenientes dos municípios de Petrópolis, Seropédica e Rio de Janeiro (Campo Grande) foram encaminhados ao SAP-PSA, para diagnóstico anátomopatológico em 1987. Adicionalmente, em 20 de março de 1987, dois fetos suínos abortados foram submetidos a exame bacteriológico e, em 23 de março de 1987, uma porca adulta, doente, foi enviada para acompanhamento clínico; após 7 dias o animal teve alta.

Exame clínico. A porca enviada viva foi mantida em uma baia individual de alvenaria, com piso de cimento, medindo $2 \times 2 \mathrm{~m}$, com bebedouro e comedouro. Recebeu ração comercial, duas vezes ao dia e água à vontade. Diariamente o animal foi avaliado com relação ao seu comportamento geral, apetite, fezes, bem como, suas freqüências cardíaca, respiratória e temperatura retal.

Necropsia. Os animais acima listados foram submetidos à necropsia (alguns foram eutanasiados in extremis) e fragmentos de diversos órgãos, principalmente, aqueles que apresentavam alterações, foram clivados em porções significativas com, no máximo, 0,5cm de espessura e fixados em formol a $10 \%$.

Histopatologia. Após a fixação em formol a 10\%, os fragmentos de órgãos foram desidratados em álcool etílico absoluto, tratados com xilol e depois embebidos e incluídos em parafina, cortados a 3-5 micrômetros, corados pela HematoxilinaEosina (HE), para serem analisados posteriormente. A coloração especial pelo Warthin-Starry também foi realizada.

Imunohistoquímica (IHQ). Amostras de intestino e linfonodo foram submetidas a técnica de IHQ (Guedes et al. 2002b) utilizando-se um anticorpo policlonal anti-L.intracellularis na diluição de 1:15.000, pelo método de avidina-biotina. O protocolo seguido para a imunoistoquímica incluiu: (1) bloqueio da atividade da peroxidase endógena pela incubação das lâminas em metanol com $3 \%$ de $\mathrm{H}_{2} \mathrm{O}_{2}$ por 15 minutos, (2) digestão prévia das lâminas em tripsina $0,1 \%$ por 15 minutos a $37^{\circ} \mathrm{C}$, (3) irradiação em forno de microondas com as lâminas imersas em 100ml de tampão citrato $\mathrm{pH}$ 6, por 2 minutos, à potência máxima, atingindo $60^{\circ} \mathrm{C}$, (4) redução de marcações inespecíficas pela incubação das lâminas em leite em pó desnatado 5\% por 20 minutos, (5) aplicação do anticorpo primário policlonal anti- $L$. intracellularis durante 45 minutos a $37^{\circ} \mathrm{C}$, (6) lavagem em solução PBS e (7) incubação com complexo avidinabiotinaperoxidase $(A B C)$ por 40 minutos, em temperatura ambiente. A revelação da reação foi obtida utilizando-se diaminobenzidina (DAB) como cromógeno.

Microscopia eletrônica. Fragmentos de íleo dos suínos foram fixados em formol a $10 \%$, lavados com buffer de sucrose a $5 \%$ (30 minutos $\times 3$ ) a $4^{\circ} \mathrm{C}$, pós-fixados com tetróxido de ósmio 


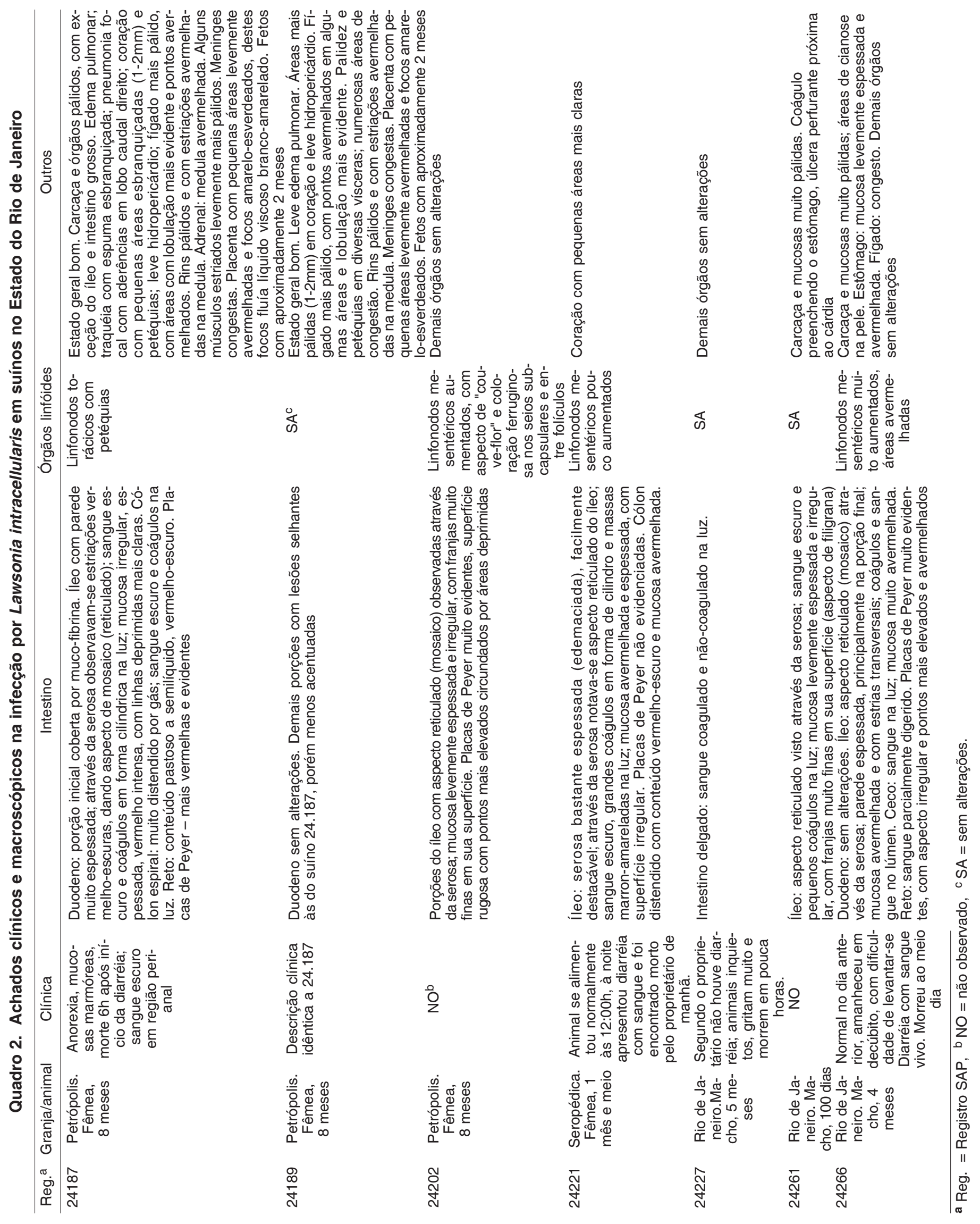


$1 \%\left(2\right.$ horas) a $4^{\circ} \mathrm{C}$, desidratados em álcool $(50,70,80,90,95$ e $100 \%$ por 10 minutos) a $4^{\circ} \mathrm{C}$ e acetona (temperatura ambiente), infiltrados com resina (1:1 e 1:2 por 90 minutos em temperatura ambiente) e polimerizados com resina pura (3 passagens de 12 horas nas temperaturas de 35,45 e $60^{\circ} \mathrm{C}$ ). Exame realizado em microscópio Zeiss Varion 10.

Bacteriologia. Os fragmentos de órgãos (pulmão, fígado e baço) e conteúdos estomacal e intestinal de 5 suínos foram inoculados e incubados por 96 horas em meio de Neil. As amostras foram semeadas em placas de Petri com conteúdo caldo coração/cérebro+ágar+sangue+antibióticos (bacitracina 15 unidades $/ \mathrm{ml}$, novobiocina 5 unidades $/ \mathrm{ml}$ e sulfato de polimixina 1 unidade/ml), incubadas à $36^{\circ} \mathrm{C}$, por 96 horas, sob condição atmosférica de microaerofilia, gerada após mistura gasosa composta de $10,0 \% \mathrm{CO}_{2}, 5,0 \%$ de $\mathrm{O}_{2}$ e $85,0 \%$ de nitrogênio (balanço). Usaram-se diversos meios de cultivo líquido (caldo brucella, caldo tripticase), semi-sólidos (tiol, tioglicolato - 0,3 ágar) e sólidos (tiol, tripticase - 0,5 ágar), em tubos e placas na tentativa do isolamento final do agente.

\section{RESULTADOS}

Histórico e epidemiologia. O primeiro surto foi observado em março de 1987, no município de Petrópolis, em uma granja com um plantel de 240 marrãs, mantidas em um sistema de manejo considerado de excelência, com boas instalações e práticas de higiene. As marrãs eram divididas em quatro lotes de 60 animais, e apenas uma delas (que havia sido levada para cobertura pelo cachaço) foi acometida pela doença. Nesse lote, a enfermidade teve início em uma baia e após disseminou-se para outras. Os animais, oito fêmeas, com 8 meses de idade, no segundo mês de gestação, apresentaram diarréia fétida enegrecida ou com sangue, vômito, hipotermia $\left(36-37^{\circ} \mathrm{C}\right)$ e morreram poucas horas depois (dois animais morreram 6 horas após o início da diarréia). Os animais foram tratados com vitamina K. As fêmeas, linhagem Camborough 15 (Duroc Pic com Landrace Pic x Large White Pic, Agroceres) que formavam o lote, no qual a doença ocorreu, vieram de uma granja multiplicadora em Paulo de Frontin, RJ, dois meses antes do surto ocorrer. A ração era feita na própria granja. Um animal doente abortou. Na propriedade vizinha, uma porca morreu com os mesmos sintomas. $O$ veterinário ainda relatou que já vira outros casos semelhantes em Ponte Nova, MG, há um ano atrás, em porcas de mesma linhagem. Em Ponte Nova, os problemas teriam surgido após a retirada da furazolidona da ração ( $100 \mathrm{~g} /$ tonelada). O segundo surto ocorreu em 15 de maio de 1987, no município de Seropédica, em leitões com aproximadamente dois meses de idade. Os sete animais, ao meio dia, estavam bem. A noite um porco apresentou diarréia com sangue e amanheceu morto (SAP 24221). Os animais eram alimentados com "lavagem" (restos de comida) e ração. O desmame era realizado aos 2 meses de idade. $O$ terceiro surto ocorreu em 26 de maio de 1988, em Campo Grande, município do Rio de Janeiro. Morreram inicialmente oito suínos, de 3 meses de idade, de um total de 200. Em 13 de julho, a doença já havia matado 20 animais. A doença afetou, sobretudo, suínos entre 60 e 90 dias. A granja contava com 70 matrizes e tinha iniciado suas atividades há dois anos e meio; as instalações eram modernas e a ração era de fabricação própria. Os suínos eram provenientes de uma granja de Petrópolis, RJ. Seis meses antes do surto ocorrer, houve alteração no manejo dos suínos em fase de crescimento (troca do antibiótico sulfametazina por outro). Segundo o proprietário, o problema havia começado há aproximadamente um ano e meio. Os animais apresentavam-se inquietos, gritavam muito e morriam em poucas horas; os animais mortos, quando "abertos", apresentavam sangue dentro dos intestinos. Um animal (SAP 24266) apresentou diarréia com sangue vivo e morreu em aproximadamente 12 horas. Os suínos (machos e fêmeas) enviados para necropsia tinham entre 100 dias e 5 meses de idade.

Aspectos clínicos. Exceto na primeira granja avaliada (propriedade em que parte dos animais morrereu em 6 horas, em boas condições corporais), as alterações mais freqüentes nos suínos ao exame clínico, foram queda do escore corporal e diarréia, na maior parte dos casos, caracterizada por fezes mais escurecidas, fétidas ou com sangue vivo. Outras alterações freqüentes foram mucosas hipocoradas a marmóreas, apatia e, por vezes, vômito. Observaram-se também hipotermia $\left(36-37^{\circ} \mathrm{C}\right)$ e, em uma porca que se recuperou, leve hipertermia $\left(39^{\circ} \mathrm{C}\right)$.

As alterações macroscópicas (Quadro 2), relativamente constantes, concentravam-se marcadamente no íleo. O órgão estava mais firme, pelo espessamento da parede, alteração bastante perceptível ao manuseio e à secção (Fig.1). Externamente, a parede apresentava aspecto reticulado de mosaico, mais pronunciado nas porções mais caudais, quando visualizada através da serosa que, por sua vez, estava espessada e brilhante, mas transparente. A mucosa era irregular, espessada com áreas hiperêmicas; em alguns animais tinha aspecto de veludo

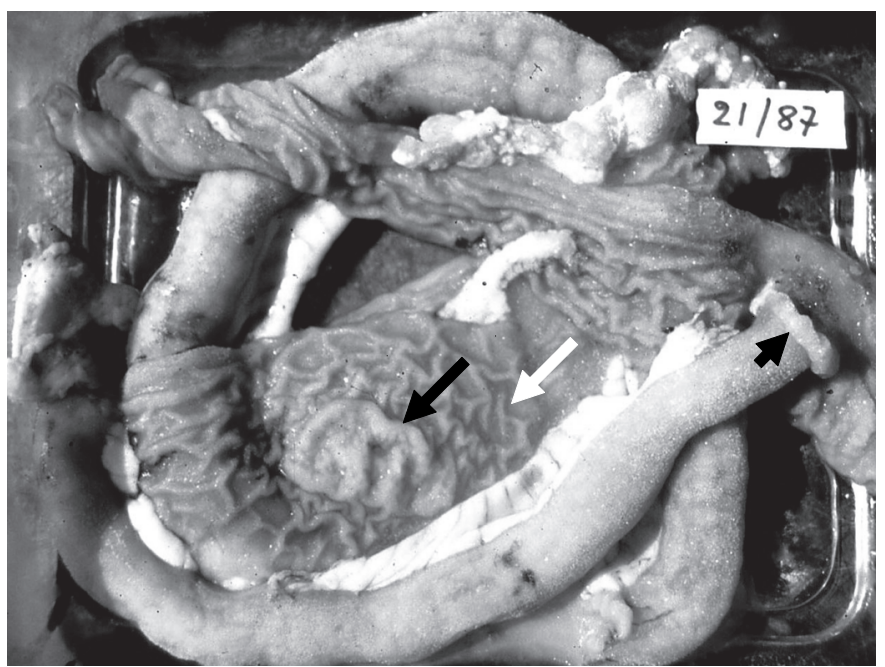

Fig. 1. Íleo mais firme com parede espessada (cabeça de seta); segmento aberto com mucosa de aspecto reticulado (seta branca) e placa de Peyer proeminente e rugosa (seta). 


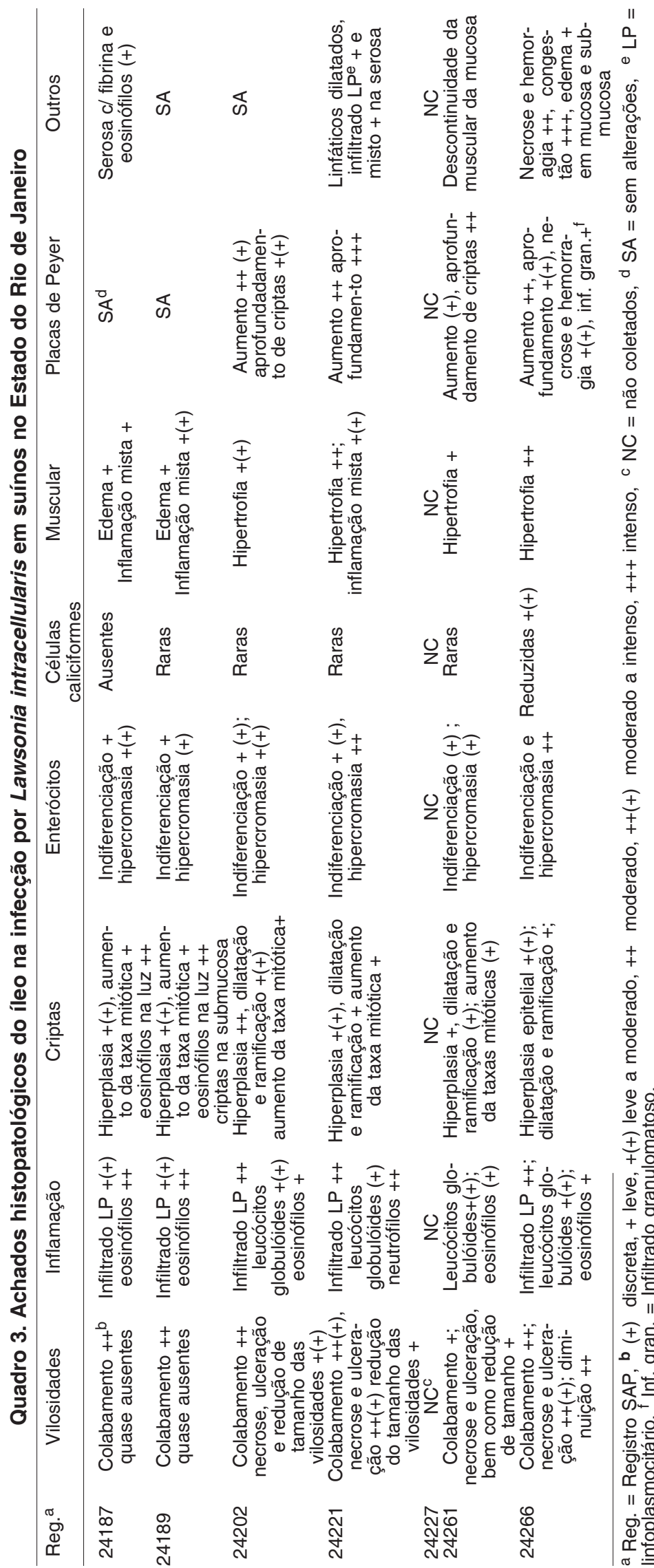

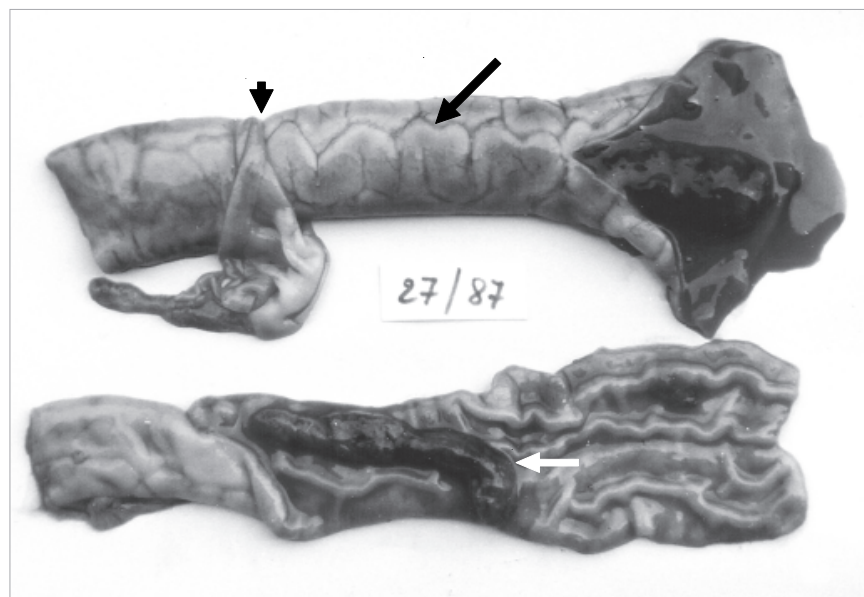

Fig. 2. Íleo com aspecto de mosaico (seta preta), visualizado através da serosa (espessada e brilhante, mas transparente; cabeça de seta). Mucosa levemente espessada, hiperêmica; coágulo sanguíneo cilíndrico (seta branca).

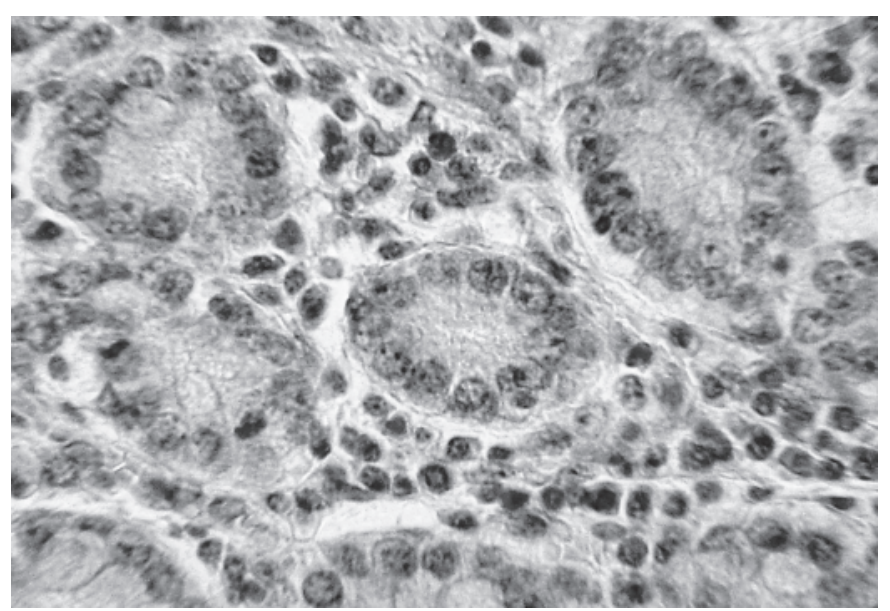

Fig. 3. Leve infiltração inflamatória mononuclear, com presença de leucócitos globulóides, entre criptas ilíacas proliferadas. HE, obj.40x.

avermelhado e em outros apresentava-se coberta por "pseudomembranas"; o conteúdo era hemorrágico, com formação de coágulos cilíndricos (Fig.2). Diversos animais apresentavam rugosidade evidente na região das placas de Peyer, que se mostravam mais elevadas (Fig.1) e, por vezes, avermelhadas. Parte dos animais apresentou cólon distendido por gás, com sangue escuro no lúmen e ceco e reto com conteúdo sanguinolento, por vezes com coágulos. Havia sangue enegrecido ao redor do ânus de alguns animais. Os linfonodos mesentéricos estavam aumentados de volume e, em alguns animais, de coloração avermelhada ou ferruginosa. Nos demais órgãos não havia alterações significativas, ou eram secundárias.

As alterações microscópicas (Quadros 3 e 4) caracterizavam-se, sobretudo, por variados graus de hiperplasia de células epiteliais das criptas, em geral com hipercromasia, indiferenciação e atividade mitótica não muito pronunciadas (Fig. 3). Algumas criptas encontra- 


\section{Quadro 4. Achados histopatológicos de outras vísceras na infecção por Lawsonia intracellularis em suínos no Estado do Rio de Janeiro}

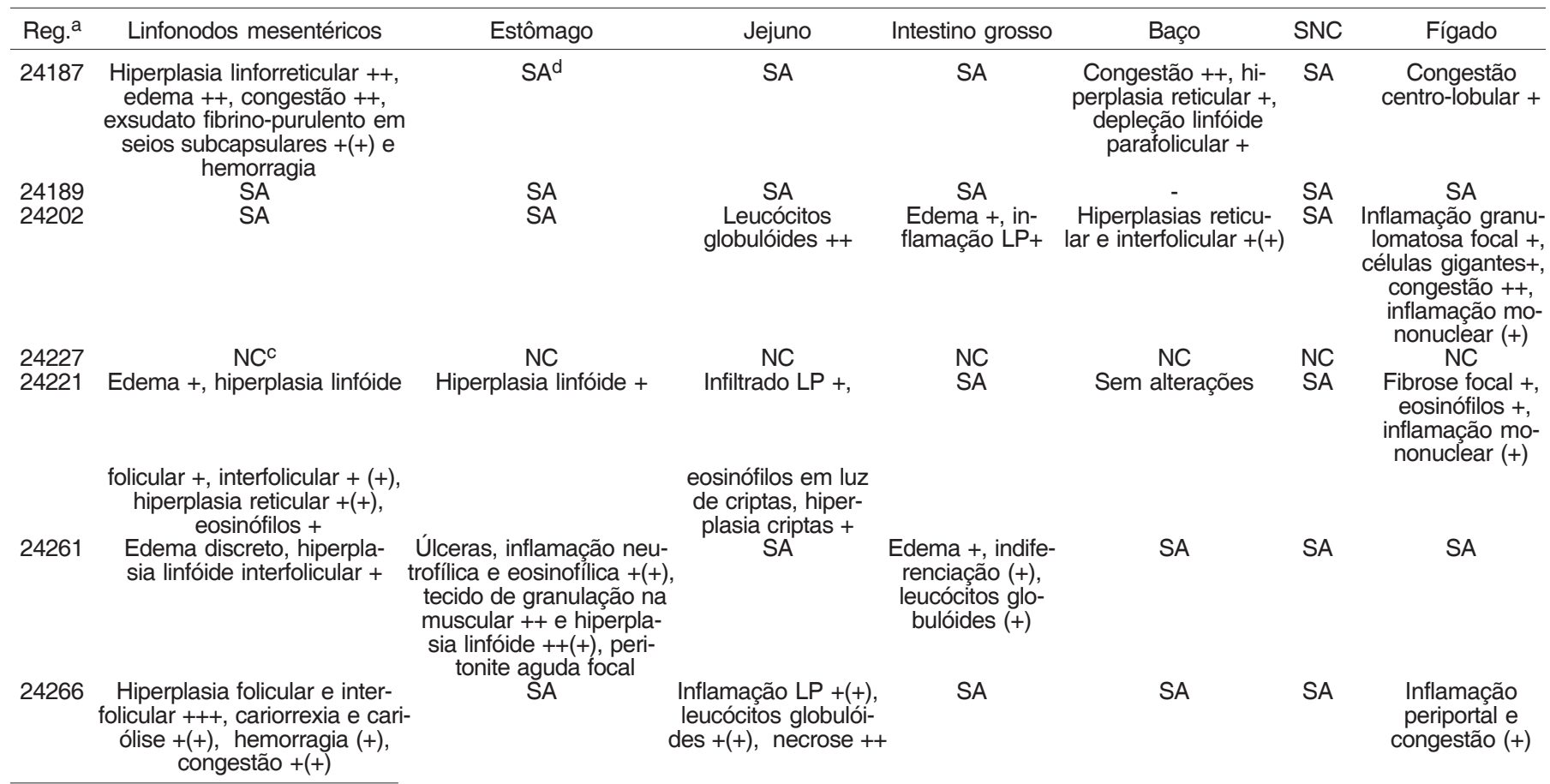

a Reg. = Registro SAP, ${ }^{b}(+)$ discreta, + leve, $+(+)$ leve a moderado, ++ moderado, $++(+)$ moderado a intenso, +++ intenso, ${ }^{c} \mathrm{NC}=$ não coletados, d $\mathrm{SA}=$ sem alterações, e LP = linfoplasmocitário.

Fig.4. Lawsonia intracelullaris em células epiteliais de vilosidades e criptas, detectada por imunohistoquímica (em marrom). Obj.20x.

Fig. 5. Lawsonia intracelullaris em células epiteliais de criptas e em macrófagos, detectada por imunohistoquímica (em marrom). Obj.40x.

Fig. 6. Lawsonia intracelullaris (em marrom), em células epiteliais de criptas, detectada por imunohistoquímica. Obj.100x.
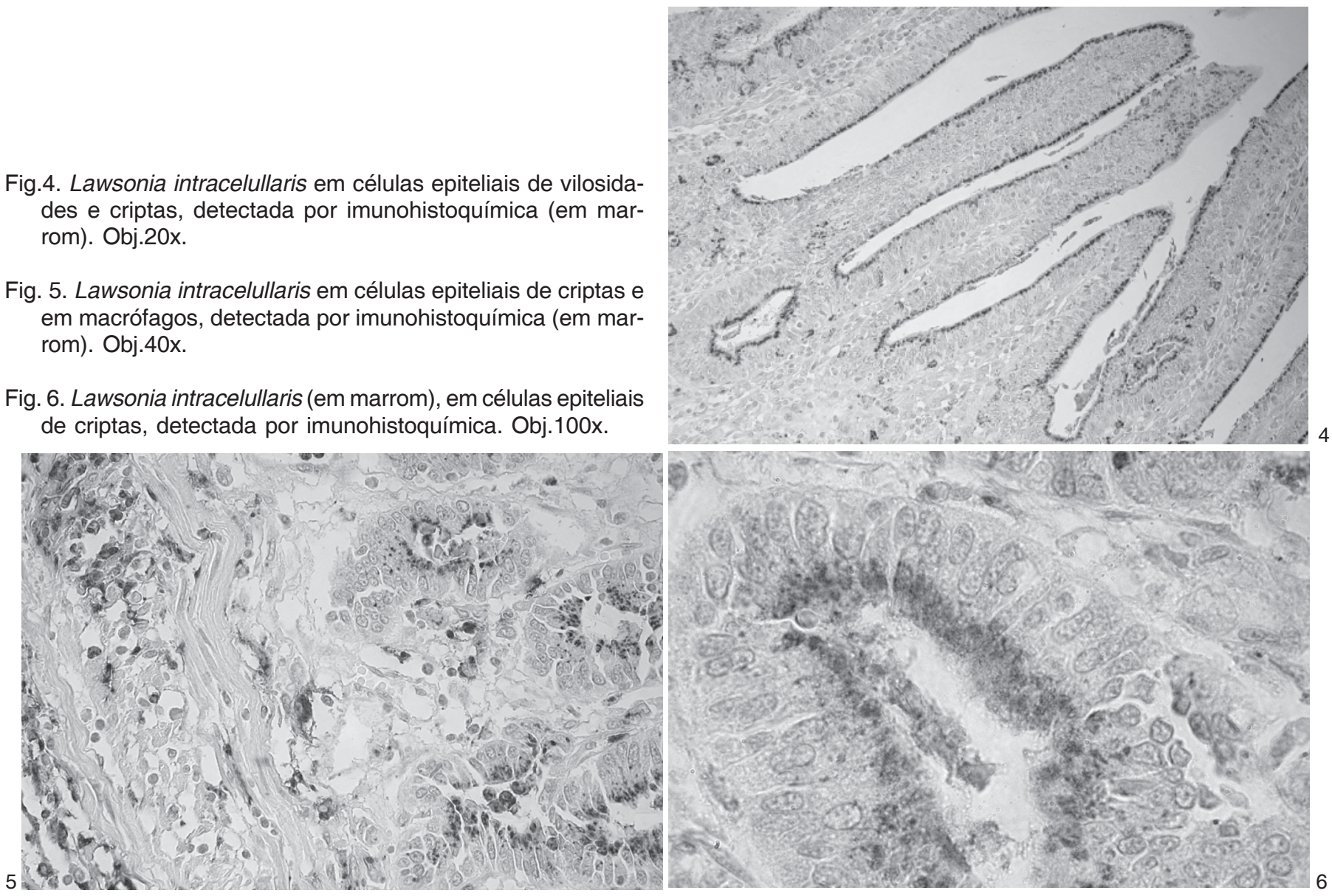
vam-se dilatadas e preenchidas por exsudato eosinofílico. Por entre as criptas proliferadas, mas também na submucosa, entre as camadas musculares e até na serosa, havia infiltração rica em eosinófilos e leucócitos globulóides (Fig.3) com presença de linfócitos e plasmócitos. Também foram observados "colabamento" (fusão) no ápice das vilosidades, redução de células caliciformes e leve hipertrofia multifocal das camadas musculares. As placas de Peyer, por vezes, encontravam-se hiperplásicas com presença de criptas no seu interior ("aprofundamento de criptas"). Havia áreas de descontinuidade da muscular da mucosa, através das quais as criptas penetravam a submucosa ("criptas na submucosa"). Em alguns animais predominavam lesões necrótico-ulcerativas, localmente extensivas, acompanhadas de grave hemorragia, mais proeminentes na metade superior da mucosa.

Bacteriologia. O exame microscópico (contraste de fase e campo escuro) feito do conteúdo do intestino delgado e grosso e de fragmentos de fígado, revelou presença de cocos móveis e imóveis e inúmeros bastonetes com características morfológicas e de motilidade típica de bactérias, à época designadas como do gênero Campylobacter. Nas placas semeadas verificou-se a presença de colônias pequenas com cerca de $1 \mathrm{~mm}$ de diâmetro, convexas, brilhantes, de cor branco-acinzentada e não-hemolíticas. O exame bacterioscópico revelou, além de alguns cocos móveis e imóveis, bastonetes Gram-negativos em forma de vírgula, asa de gaivota e "s", que caracterizavam o referido gênero, hoje Lawsonia. As tentativas de isolamento final do agente para sua caracterização bioquímica não tiveram êxito.

Imunohistoquímica. Os suínos (SAP 24187 e 24189) apresentaram, no íleo, marcação positiva com anticorpo policlonal anti-Lawsonia intracellularis no epitélio de criptas intestinais, vilosidades e em placas de Peyer (Fig.4, 5 e 6).

Microscopia eletrônica. A microscopia eletrônica, realizada em fragmentos de intestino de porcos, revelou que estas formas realmente são bactérias, morfologicamente indistinguíveis das descritas ultramicroscopicamente como Lawsonia intracellularis.

\section{DISCUSSÃO}

O diagnóstico de Enteropatia Proliferativa Hemorrágica (EPH) em suínos baseou-se nos aspectos clínico-patológicos característicos para a enfermidade e foi confirmado pela demonstração imunohistológica de Lawsonia intracellularis no intestino e pela detecção da bactéria em enterócitos através de microscopia eletrônica. Os exame bacteriológicos corroboraram com o diagnóstico.

Quanto à observação de possíveis fatores predisponentes, no primeiro surto em suínos, que ocorreu em Petrópolis, houve relato de condições claramente associadas à EPH. Havia histórico de enfermidade semelhante em uma propriedade vizinha - o que sugere a possibilidade de introdução do agente (Love et al. 1977, Mauch \& Bilkei 2005) - bem como a interrupção do uso contínuo de antibióticos na alimentação, o que está de acordo com as observações de Mauch \& Bilkei (2005), para quem o uso contínuo de antibióticos cria populações susceptíveis às formas agudas da enfermidade. É possível que o surto observado na granja de Campo Grande, Rio de Janeiro, tenha origem em animais provenientes de Petrópolis. Outros fatores, como estresse, que poderia ser desencadeado por acasalamento ou por parto (Love et al. 1977) ou mudanças ambientais significativas (Lemarchand et al. 1997), bem como o tamanho do plantel (Stege et al. 2000), igualmente só puderam ser associados ao primeiro surto (em Petrópolis), uma vez que a doença acometeu marrãs prenhes, no segundo mês de gestação.

A enfermidade se desenvolveu de forma variada, tanto em relação aos sintomas, quanto em relação às faixas etárias acometidas nos diferentes surtos. No primeiro, a doença acometeu marrãs, como descrito por Mauch \& Bilkei (2005), nos dois outros, em Campo Grande e Seropédica, a doença concentrou-se em animais entre as fases de desmame e terminação, como relatado por diversos outros autores (Ségales et al. 2001, Kyriakis et al. 2002, Alexopoulos et al. 2006). Em suínos, muitos autores têm creditado a diferença entre casos de Enterite Proliferativa (não-complicada, mais leve) e Enterite Proliferativa Hemorrágica (EPH), a diferenças na resposta imunológica (Smith \& Lawson 2001). Evidências clínicas suportam essa idéia, pois EPH geralmente ocorre em animais maduros e casos não-complicados de EP ocorrem em jovens em crescimento (Rowland \& Lawson 1992). Por outro lado, em alguns surtos de EPH, lactentes também podem ser afetados (Rowland \& Rowntree 1972). A diferença clínica entre essas duas condições, porém é importante; em geral, EPH é altamente letal e Adenomatose Intestinal Suina (AIS) e EP são condições relativamente inócuas (Smith \& Lawson 2001). Ainda no primeiro surto, a evolução foi superaguda; muitos animais foram a óbito entre 6 e 18 horas após o início dos sintomas. Guedes et al. (2002a) também descrevem quadro de EPH semelhante, com diarréia profusa e sangue, que determinava a morte em menos de 12 horas após o início dos sintomas. Em dois dos três surtos, foram verificados casos de hematoquesia intensos, a tal ponto de as paredes da baia ficarem tingidas de sangue.

Como observado por diversos autores (Love et al. 1977, Rowland \& Hutchings 1978, McOrist et al. 1992, Guedes et al. 2002b, Boesen et al. 2004), as lesões macroscópicas associadas à EP foram mais expressivas no íleo; outros segmentos intestinais apresentavam lesões mais discretas (Morés et al. 1985, Jones et al. 1993, McOrist et al. 1993, Segalés et al. 2001). Geralmente, havia lesões necrótico-hemorrágicas, além das lesões proliferativas características. Em alguns animais, verificaram-se ainda lesões em outras vísceras, porém aparentemente secundárias ao processo intestinal. Tanto a variação no grau de manifestação da doença, quanto a ocorrência de quadros hemorrágicos e necróticos, são semelhantes às descrições de surtos naturais de EP no Brasil (Morés et al. 
1985) e em outros países (Rowland \& Lawson 1975, Jensen et al. 2000, Guedes et al. 2002a, Mauch \& Bilkei 2005, McOrist 2005). Assim, de uma forma geral, as lesões clássicas relacionadas à EP, nos casos apresentados no presente estudo - hiperplasia das células crípticas, com hipercromasia e em arranjo pseudoestratificado, assim como os diferentes tipos de infiltrados inflamatórios observados - são compatíveis com as descritas para a variedade de quadros microscópicos da doença descrita em suínos (Rowland \& Lawson 1975, Morés et al. 1985, McOrist et al. 1992).

Não foi encontrada, na revisão de literatura, relação entre os leucócitos globulóides, presentes de forma significativa nas lesões proliferativas de diversos suínos e EPS, de forma que o significado de sua presença permanece não determinado. Por outro lado, estas células têm sido associadas à intensificação de respostas imunomediadas (Finn \& Schwartz 1972), de modo que talvez possam ser relacionadas à defesa local contra as bactérias infectantes, no caso, Lawsonia intracellularis.

\section{REFERÊNCIAS}

Alderton M.R. 1993. Proliferative enteritis: endemic in Australian piggeries? Aust. Vet. J. 70:311.

Alexopoulos C., Tassis P.D., Kyriakis C.S., Tzika E.D., Papatsiros V. \& Kyriakis S.C. 2006. First experience on the effect of in-feed lincomycin for the control of proliferative enteropathy in growing pigs. J. Vet. Med. A 53:157-162.

Barcellos D.E.S.N., Fallavena L.C.B. \& Jacobi H. 1992. Enteropatia proliferativa hemorrágica como causa de diarréia em suínos, no Estado do Rio Grande do Sul. Arq. Fac. Vet. UFRGS 20:21-33.

Biester H.E. \& Schwarte L.E. 1931. Intestinal adenoma in swine. Am. J. Pathol. 7:175-185.

Boesen H.T., Jensen T.K., Schmidt A.S., Jensen B.B., Jensen S.M. \& Moller K. 2004. The Influence of diet on Lawsonia intracellularis colonization in pigs upon experimental challenge. Vet. Microbiol. 103:35-44.

Cooper D.M., Swanson D.L. \& Gebhart C.J. 1997. Diagnosis of proliferative enteritis in frozen and formalin-fixed, paraffin-embedded tissues from a hamster, horse, deer and ostrich using a Lawsonia intracellularis-specific multiplex PCR. Vet. Microbiol. 54:47-62.

Dittmar M., Hoelkle K., Hoelkle K., Sydler T., Corboz L., Miserez R. \& Wittenbrink M. 2003. Diagnosis of Porcine Proliferative Enteropathy: Detection of Lawsonia intracellularis by pathological examinations, Polymerase Chain Reaction and cell culture inoculation, J. Vet. Med. 50:332-338.

Driemeier D., Faccini G.S., Oliveira R.T., Colodel E.M., Traverso S.D. \& Cattani C. 2002. Silver staining combined with alcian blue and hematoxylin-eosin for the detection of Lawsonia intracellularis in swine proliferative enteropathy, Acta Histochem. 104(3):285-287.

Duhamel G.E., Klein E.C., Elder R.O. \& Gebhart C.J. 1998. Subclinical proliferative enteropathy in sentinel rabbits associated with Lawsonia intracellularis. J. Comp.Pathol. 35:300-303.

Faccini G.S., Guedes R.M.C., Pescador C.A., Cruz C.E.F. \& Driemeier D. 2005. Diagnóstico histoquímico e imunoistoquímico da enteropatia proliferativa (Lawsonia intracellularis) em suínos. Arq. Bras. Med. Vet. Zootec. 57(5):569-575.

Finn J.P. \& Schwartz L.W. 1972. A neoplasm of globule leukocytes in the intestine of a cat. J. Comp. Pathol. 82:323-328.

Gebhart C.J., Ward G.E., Chang. K. \& Kurt Z.H. 1983. Campylobacter hyointestinalis (new species) isolated from swine lesion of proliferative ileitis. Am. J. Vet. Res. 44(3)361-367.

Guedes R.M., Gebhart C.J., Armbruster G.A. \& Roggow B.D. 2002a. Serological follow-up of a repopulated swine herd after an outbreak of proliferative hemorrhagic enteropathy, Can. J. Vet. Res. 66:258-263.

Guedes R.M., Gebhart C.J., Wilkelman N., Mackie-Nuss R.A., Marsteller T.A. \& Deen J. 2002b. Comparison of different methods for diagnosis of porcine proliferative enteropathy. Can. J. Vet. Res. 66: 99-107.

Jacobson M., Segerstad C.H., Gunnarsson A., Fellström C., de Verdier Klingenberg K., Wallgren P. \& Jensen-Waern M. 2003. Diarrhoea in the growing pig: a comparison of clinical, morphological and microbial findings between animals from good and poor performance herds, Res. Vet. Sci. 74:163-169.

Jensen T.K., Moller K., Lindecrona B. \& Jorsal, S.E. 2000. Detection of Lawsonia intracellularis in the tonsils of pigs with proliferative enteropathy. Res. Vet. Sci. 68:23-32.

Jones G.F., Ward G.E., Murtaugh M.P., Lin G. \& Gebhart C.J. 1993. Enhanced detection of intracellular organism of swine proliferative enteritis, ileal symbiont intracellularis, in feces by polymerase chain reaction. J. Clin. Microbiol. 31(10):2611-2615.

Koyama T., Hirai T. \& Nagai S. 2006. In vitro cultivation and partial characterization of Lawsonia intracellularis from a Japanese field case of Porcine Proliferative Enteropathy, J. Vet. Med. Sci. 68(8):609-611.

Kyriakis S.C., Alexopoulos C., Saoulidis K., Lekkas S., Milliotis C.C. \& Sauveroche B. 2002. The effect of josamycine on the control of ileitis in weaned piglets under field conditions. J. Vet. Pharmacol. Therap. 25:279-284

Lawson G.H.K. \& Rowland A.C. 1974. Intestinal adenomatosis in the pig: A bacteriological study. Res. Vet. Sci. 17:331-336.

Lemarchand T.X., Tully T.N., Shane S.M. \& Duncan D.E. 1997. Intracellular Campylobacter-like organism associated with rectal prolapse and proliferative enteroproctitis in emus (Dromaius novaehollandiae). Vet. Pathol. 34:152-156.

Love R.N., Love D.N. \& Edwards M.J. 1977. Proliferative Haemorrhagica enteropathy in pigs. Vet. Rec. 100(4):65-68.

Mapother M.E., Joens L.A. \& Glock R.D. 1987. Experimental reproduction of porcine proliferative enteritis. Vet. Rec. 121:533-536.

Mauch C.P. \& Bilkei G. 2005. Reproductive performance of gilts following na outbreak of acute proliferative enteropathy due to Lawsonia intracellularis. Vet. J. 170:128-131.

McOrist S. 2005. Defining the full costs of endemic porcine proliferative enteropathy. Vet. J. 170:8-9.

McOrist S., Boid R. \& Lawson G.H.K. 1989. Antigenic analysis of Campylobacter species and an intracellular Campylobacter-like organism associated with Porcine Proliferative Enteropathies. Infect. Immun. 57(3)957-962.

McOrist S., Maclntyre N., Stokes C.R. \& Lawson G.H.K. 1992. Immunocytological responses in porcine proliferative enteropathies. Infect. Immun. 60:4184-4191.

McOrist S., Jasni S., Mackie R., MacIntyre N., Neef N. \& Lawson G. 1993. Reproduction of porcine proliferative enteropathy with pure cultures of ileal symbiont intracellularis. Infect. Immun. 61(10):42864292.

McOrist S., Gebhart C.J., Boid R. \& Barns S.M. 1995. Characterization of Lawsonia-intracellularis gen-nov, sp-nov, the obligately intracellular bacterium of porcine proliferative enteropathy, Int. J. Syst. Bacteriol. 45(4):820-825.

McOrist S., Roberts L., Jasni S., Rowland A.C., Lawson G.H.K, Gebhart C.J. \& Bosworth B. 1996. Developed and resolving lesions in porcine proliferative enteropathy: possible pathogenic mechanisms. J. Comp. Pathol. 115:35-45.

Morés N., Neves D.S., Nogueira R.H.G. \& Guimarães E.B. 1985. Diagnósticos clínico e Anátomo-histológicos de casos espontâneos de 
Enteropatia Proliferante e Hemorrágica $(\mathrm{EPH})$ em suínos. Arq. Bras. Med. Vet. Zootec. 37(1):29-37.

Rowland A.C. \& Hutchings D.A. 1978. Necrotic enteritis and regional ileitis in pigs at slaughter. Vet. Rec. 103(15):338-339.

Rowland A.C. \& Lawson G.H.K. 1975. Porcine intestinal adenomatosis: a possible relationship with necrotic enteritis, regional ileitis and proliferative haemorrhagic enteropathy. Vet. Rec. 97(10):178-180.

Rowland A.C. \& Lawson G.H.K. 1992. Porcine proliferative enterophaties, p.560-569. In: Leman A.D., Straw B.E., Mengeling W.L., D’Allaire S. \& Taylor D.J. (ed.), Diseases of Swine. $7^{\text {th }}$ ed. lowa State University Press, Ames.

Rowland A.C. \& Rowntree P.G.M. 1972. Haemorrhagic Bowel Syndrome associated with intestinal adenomatosis in the pig. Vet. Rec. 91:235241.

Schauer D.B., McCathey S.N., Daft B.M., Jha S.S., Tatterson L.E., Taylor N.S. \& Fox J.G. 1998. Proliferative Enterocolitis associated with dual infection with enteropathogenic Escherichia coli and Lawsonia intracellularis in rabbits. J. Clin. Microbiol. 36(6):1700-1703.

Segalés J, Fernández-Salguero J.M., Fructuoso G., Quintana J., Rosell J., Pozo J., Arriba M.L, Rubio M. \& Domingo J. 2001. Granulomatous enteritis and lymphadenitis in Iberian pigs naturally infected with Lawsonia intracellularis. Vet. Pathol. 38(3):343-346.

Smith D.G.E. \& Lawson GH. 2001. Lawsonia intracellularis: getting inside the pathogenesis of proliferative enteropathy. Vet. Microbiol. 82(4)331345.

Stege H., Jensen T.K., Möller K., Baekbo P. \& Jorsal S.E. 2000. Prevalence of intestinal pathogens in Danish finishing pig herds. Prev. Vet. Med 46(4):279-292.

Umemura T., Tsuchitani M., Totsuka M., Narame I. \& Yamachiro S. 1982. Histiocytic enteritis of rabbits. Vet. Pathol. 19:326-28.

Wuersch K., Huessy D. \& Koch K. 2006. Lawsonia intracellularis Proliferative Enteropathy in a filly. J. Vet. Med. 53:17-21. 